\title{
Relationship between soil moisture and vegetation in the Kairouan plain region of Tunisia using low spatial resolution satellite data
}

\author{
M. Zribi, ${ }^{1}$ T. Paris Anguela, ${ }^{2}$ B. Duchemin, ${ }^{1}$ Z. Lili, ${ }^{3}$ W. Wagner, ${ }^{4}$ S. Hasenauer, ${ }^{4}$ \\ and A. Chehbouni ${ }^{1}$ \\ Received 13 May 2009; revised 23 November 2009; accepted 5 January 2009; published 15 June 2010.
}

[1] The present paper proposes an empirical approach for the modeling of vegetation development, using moisture measurements only. The study is based simply on the use of two databases: one containing soil moisture products derived from ERS scatterometer data over the period 1991-2006 and the other containing normalized difference vegetation indices (NDVI) derived from advanced very high resolution radiometer over the period 1991-2000. The study is applied over the Kairouan plain, the central semiarid region of Tunisia (North Africa). Soil moisture products were first validated on the basis of comparisons with Global Soil Wetness Project, Phase 2 Data, outputs and rainfall events. The soil moisture distribution during the rainy period between October and May is described and is found to be correlated with the vegetation dynamics estimated using the NDVI products. Finally, a semiempirical model is proposed, based on satellite moisture and NDVI products, which allows the NDVI value to be estimated for a period of 1 month during the rainy season as a function of the moisture profile estimations obtained during the previous months. This approach could prove very useful and provide a simple tool for the modeling of vegetation dynamics during rainy seasons in semiarid regions.

Citation: Zribi, M., T. Paris Anguela, B. Duchemin, Z. Lili, W. Wagner, S. Hasenauer, and A. Chehbouni (2010), Relationship between soil moisture and vegetation in the Kairouan plain region of Tunisia using low spatial resolution satellite data, Water Resour. Res., 46, W06508, doi:10.1029/2009WR008196.

\section{Introduction}

[2] In semiarid regions, and northern Africa in particular, the absence of rainfall, together with the occurrence of long periods of drought, represent one of the main environmental factors having a negative effect on agricultural productivity. The evaluation of vegetation cover and the monitoring of hydric stress are indispensable in these regions, particularly in areas with pluvial agriculture. The challenge is to develop an approach for the monitoring of vegetation cover and drought, which can contribute toward the making of appropriate and timely decisions in response to drought. A variety of drought-monitoring products are used to generate a map, including precipitation indices, streamflow levels, soil moisture models, snowpack levels, and satellite vegetation index data [Heim, 2002; Ntale and Gan, 2003; Dai et al., 2004]. The spatially and temporally continuous coverage offered by satellite data enhances the value of these drought-monitoring products.

[3] The value of meteorological satellite imagery for the investigation of the vitality and phenology of vegetation has been well demonstrated [Tucker, 1979; Goward et al., 1985; Peters et al., 1997]. As a consequence of its twice-daily

\footnotetext{
${ }^{1}$ CESBIO (CNRS, CNES, IRD, UPS), Toulouse, France.

${ }^{2}$ LATMOS, Vélizy, France.

${ }^{3}$ INAT, Tunis-Mahrajène, Tunisia.

${ }^{4}$ Institute of Photogrammetry and Remote Sensing, Vienna University of Technology, Vienna, Austria.
}

coverage and synoptic view characteristics, the advanced very high resolution radiometer (AVHRR), one of the Earth observing instruments carried by the National Oceanic and Atmospheric Administration's (NOAA) satellites, is currently the instrument of choice for recording global, coarseresolution images of the Earth. The normalized difference vegetation index (NDVI), derived from AVHRR data, has been extensively used for vegetation monitoring, crop yield assessment and drought detection [Moulin et al., 1997; Anyamba and Tucker, 2005; Barbosa et al., 2006].

[4] Nicholson and Farrar [1994] and Farrar et al. [1994] analyzed the relationship between rainfall and NDVI. These studies note significant differences in the NDVI-rainfall relationship for various types of soil. Richard and Poccard [1998] demonstrated the NDVI's sensitivity to seasonal and interannual rainfall variations in southern Africa. Funk and Brown [2006] have proposed a simple model for producing 1 to 4 month NDVI projections. These statistical projections are based on satellite rainfall estimates and relative humidity demand. All of these studies rely on the high correlation between precipitation and vegetation development. Soil water storage is the efficient component of precipitation, which is used to stimulate the growth of vegetation. The other components, that is, evaporation loss and runoff, are particularly dependent on variations in soil type and climatic conditions for any given study site. Therefore, in the present study, we propose to analyze the relationship between soil moisture and vegetation development, using satellite databases for moisture and vegetation only, for a semiarid region, the Kairouan plain, in Tunisia (North Africa). 


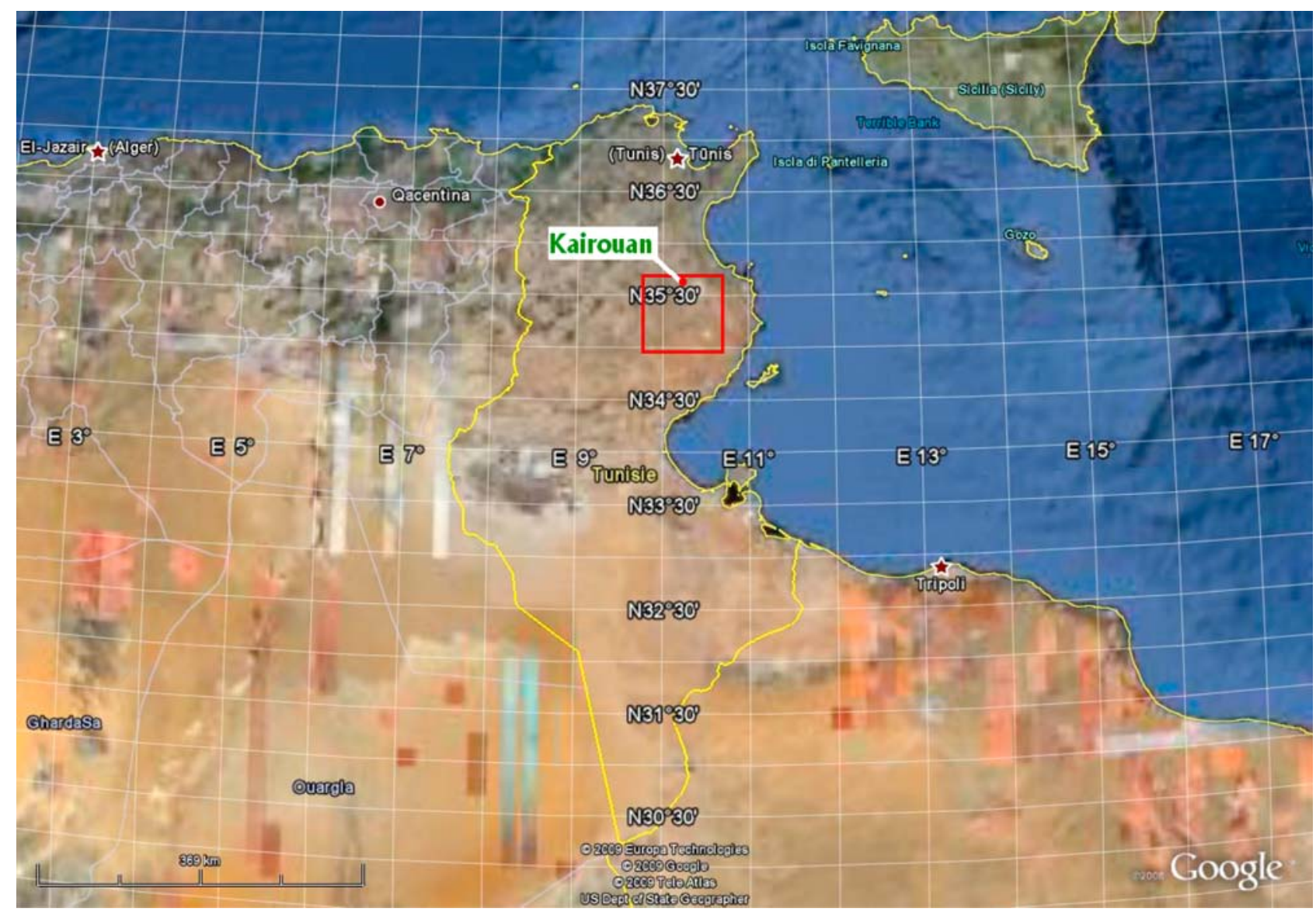

Figure 1. Location of the Kairouan plain $\left(9^{\circ} 30^{\prime} \mathrm{E}-10^{\circ} 15^{\prime} \mathrm{E}, 35^{\circ} \mathrm{N}-35^{\circ} 45^{\prime} \mathrm{N}\right)$.

[5] Our objective is to propose a simple tool for the forecasting of vegetation development, based on moisture measurements only, without making use of climate data, which can be particularly useful during periods of drought. Soil moisture, which is a key factor in hydrological modeling and the determination of land surface boundary conditions, has a clear influence on surface-atmosphere interactions and subsequently has the potential of strongly affecting weather patterns, hydrological variations and vegetation development [Beven and Fisher, 1996; Koster et al., 2004; Saux-Picart et al., 2010]. In the last two decades, considerable efforts have been made to develop remote sensing techniques for the characterization of the spatial and temporal variability of soil parameters at regional and global scales. In particular, in the case of soil moisture, active and passive microwave techniques, as well as interpretation tools, have been developed [Jackson et al., 1996; Ulaby et al., 1996; Paloscia et al., 2008]. The effectiveness of low-resolution spaceborne scatterometers (active microwave) for land surface characterization has been demonstrated by a large number of studies related to moisture estimation [Wagner et al., 1999a; Zribi et al., 2003, 2008; Ceballos et al., 2005; Pellarin et al., 2006; Paris Anguela et al., 2008]. Considerable progress has been made in determining soil moisture, and in evaluating feedback effects between moisture and climate, at regional and global scales [Brubaker and Entekhabi, 1996; Entekhabi et al., 1996; Eltahir and Gong, 1996; Douville et al., 2001; Walker and Houser, 2001].
[6] The present paper is organized as follows: Section 2 presents the study site, together with a brief description of satellite data used in our analysis. Section 3 discusses the evaluation of ERS moisture products on the basis of a comparison with the Global Soil Wetness Project, Phase 2 Data (GSWP-2), output moisture product and rainfall data. It also provides details of the soil moisture's statistical behavior. Section 4 proposes an analysis of the correlation of moisture with vegetation dynamics, and the development of a simple approach for the estimation of vegetation dynamics as a function of the soil moisture profile during the rainy season (October-May). Finally, our conclusions are presented in section 5 .

\section{Study Area and Data}

\subsection{Study Area}

[7] The Kairouan plain [Leduc et al., 2007] is situated in central Tunisia $\left(9^{\circ} 30^{\prime} \mathrm{E}-10^{\circ} 15^{\prime} \mathrm{E}, 35^{\circ} \mathrm{N}, 35^{\circ} 45^{\prime} \mathrm{N}\right.$ ), (Figure 1). The climate in this region is semiarid, with an average annual rainfall of approximately $300 \mathrm{~mm}$ per year, characterized by a rainy season lasting from October to May, with the two rainiest months being October and March. As is generally the case in semiarid areas, the rainfall patterns in this area are highly variable in time and space: the extreme values recorded in the Kairouan are $108 \mathrm{~mm}$ in 1950/51 and $703 \mathrm{~mm}$ in $1969 / 70$. The mean temperature in Kairouan City is $19.2^{\circ} \mathrm{C}$ (minimum of $10.7^{\circ} \mathrm{C}$ in January and maximum of $28.6^{\circ} \mathrm{C}$ in 
August). The winter is cool in the northwest of the site and temperate elsewhere. The relative humidity varies between $70 \%$ and $55 \%$ in winter and $40 \%$ and $55 \%$ in summer. The annual Piche evaporation measured in the Kairouan is $2070 \mathrm{~mm}$, whereas the mean annual potential evapotranspiration (Penman) is close to $1600 \mathrm{~mm}$.

[8] The landscape is mainly flat. The vegetation in this area is dominated by agriculture (cereals, olive and fruit trees and market garden). Crops are various and their rotation is typical of semiarid regions.

[9] In the past, most of the surface flow feeding the Kairouan plain came from the three main catchments (Zeroud, Merguellil and Nebhana), which are presently cut off by large dams. The aquifer of the Kairouan plain represents the largest basin in central Tunisia. It is fed by the infiltration of surface waters (Zeroud and Merguellil) during floods in the natural regime, or at the time of dam releases since the construction of the Sidi Saad and El Haouareb dams [Lacombe et al., 2008]. Surface and groundwater flows are drained into Sebkha Kelbia, a large salt lake.

\subsection{Satellite Data}

[10] For the purposes of the present study, we propose to use two long temporal series of satellite data. For the moisture estimations, it was decided to work with the European Remote Sensing Satellite (ERS) scatterometer soil moisture product, provided by the Vienna University of Technology [Wagner et al., 1999b]. ERS scatterometer has the advantage of providing soil moisture data twice per week, of being freely available (http://www.ipf.tuwien.ac.at/radar), and of having provided global spatial coverage since 1991. Our study is based on 11 years of data, collected between 1992 and 2006. For the characterization of the vegetation in this region, we made use of NDVI products derived from AVHRR data between 1991 and 2000.

\subsubsection{ERS Scatterometer Data}

[11] The ERS scatterometer radar (active microwave) operates in the $\mathrm{C}$-band $(5.3 \mathrm{GHz})$ using vertical polarization. It is carried by the European Remote Sensing Satellites ERS-1 (1991-1996) and ERS-2 (1995 up to present). Data sets are not available for the period between 2001 and the end of 2003, owing to technical problems on the ERS-2 satellite. Over land, the measured radar backscattering coefficient depends on soil moisture, surface roughness, vegetation characteristics and the incidence angle of the transmitted radar beam. Soil moisture data is retrieved from the backscattering coefficient using a change detection method developed at the Institute of Photogrammetry and Remote Sensing (IPF), Vienna University of Technology (TU-Wien) and described by Wagner et al. [1999a, 1999b]. This method has been applied with success over different climatic regions, the Canadian Prairies [Wagner et al., 1999a], the Iberian Peninsula [Wagner et al., 1999c], Ukraine [Wagner et al., 1999b], and Western Africa [Wagner and Scipal, 2000].

[12] In the TU-Wien model, long-term scatterometer data is used to model the incidence angle dependence of the radar backscattering signal $\sigma^{\circ}$. Once the incidence angle dependence has been determined, the backscattering coefficients $\sigma^{\circ}$ are normalized to a reference incidence angle $\left(40^{\circ}\right)$. Finally, the relative soil moisture data, ranging between $0 \%$ and $100 \%$, are derived by scaling the normalized backscattering coefficients $\sigma^{\circ}(40)$ between the lowest/highest $\sigma^{\circ}(40)$ values corresponding to the driest/wettest soil conditions [Wagner, 1998].

[13] The derived soil moisture product, the surface soil moisture $\left(\mathrm{m}_{\mathrm{s}}\right)$, represents the water content in the first $5 \mathrm{~cm}$ of the soil in relative units, which range between extremes corresponding to totally dry conditions, and total saturated water capacity. The spatial resolution corresponds to cells of approximately $50 \mathrm{~km}$, with $25 \mathrm{~km}$ grid spacing. The temporal resolution of the data is approximately two measurements per week.

[14] In order to compare $m_{s}$ values with surface modeled moisture, $m_{\mathrm{s}}$ products were converted to physical units of $\mathrm{m}^{3} \mathrm{~m}^{-3}$ by using the $90 \%$ confidence interval of a Gaussian distribution [Pellarin et al., 2006] equal to $\mu \pm 1.65^{*} \sigma$, where $\mu$ and $\sigma$ are the mean and the standard deviation of simulated data (depending on which soil moisture product $m_{s}$ is compared to) in volumetric units, respectively:

$$
\theta(t)=m_{s}(t) *\left(\theta_{\max }-\theta_{\min }\right)+\theta_{\min },
$$

where $\theta(t)$ is the soil moisture content at a time $t\left[\mathrm{~m}^{3} \mathrm{~m}^{-3}\right]$, $m_{s}(t)$ is the ERS scatterometer surface soil moisture [-] at a time $t, \theta_{\max }$ is the maximum wetness value $\left[\mathrm{m}^{3} \mathrm{~m}^{-3}\right]$ equal to $(\mu+1.65 * \sigma)$, and $\theta_{\min }$ is the minimum wetness value $\left[\mathrm{m}^{3} \mathrm{~m}^{-3}\right]$ equal to $(\mu-1.65 * \sigma)$.

[15] With the aim to investigate the soil moisture content in the soil profile, a two-layer water model [Wagner et al., 1999 b] was used to obtain root-zone soil moisture from surface soil moisture radar measurements, $m_{s}$. The Soil Water Index (SWI) data was derived from $m_{s}$ using equation (1) and represents the root-zone soil moisture content in the first meter of the soil in relative units ranging between wilting point and field capacity:

$$
S W I(t)=\frac{\sum_{i} m_{s}\left(t_{i}\right) e^{-\left(t-t_{i}\right) / T}}{\sum_{i} e^{-\left(t-t_{i}\right) / T}} \quad \text { for } \quad t_{i} \leq t
$$

where $m_{s}\left(t_{i}\right)$ is the surface soil moisture estimate at time $t_{i}$. At time $t$, all measurements taken within a period $[t, \mathrm{t}-3 T]$ are taken into consideration if at least four measurements have been recorded within the most recent time period $[t, t-T]$. The parameter $T$, called the characteristic temporal period, represents the time scale of soil moisture variations. In the present case, $T$ is set equal to 10 days. These products have already been used in different environment studies [Ceballos et al., 2005; Pellarin et al., 2006; Paris Anguela et al., 2008].

[16] Figure 2 illustrates the $m_{s}$ surface soil moistures over the study sites for two dates. The data recorded on the first date (20 February 1994) is affected by a strong spatial variability, linked to the local precipitation. Soil moisture shows a high heterogeneity with a variation between $15 \%$ and $100 \%$ at the northwestern area. The second date (23 February 1994) corresponds to an approximately homogenous low state of moisture, after drying over the study site.

\subsubsection{NDVI Data}

[17] The normalized difference vegetation index (NDVI) is acquired by the advanced very high resolution radiometer (AVHRR). This index, given by the ratio between the difference between the visible and near-infrared channels, and 

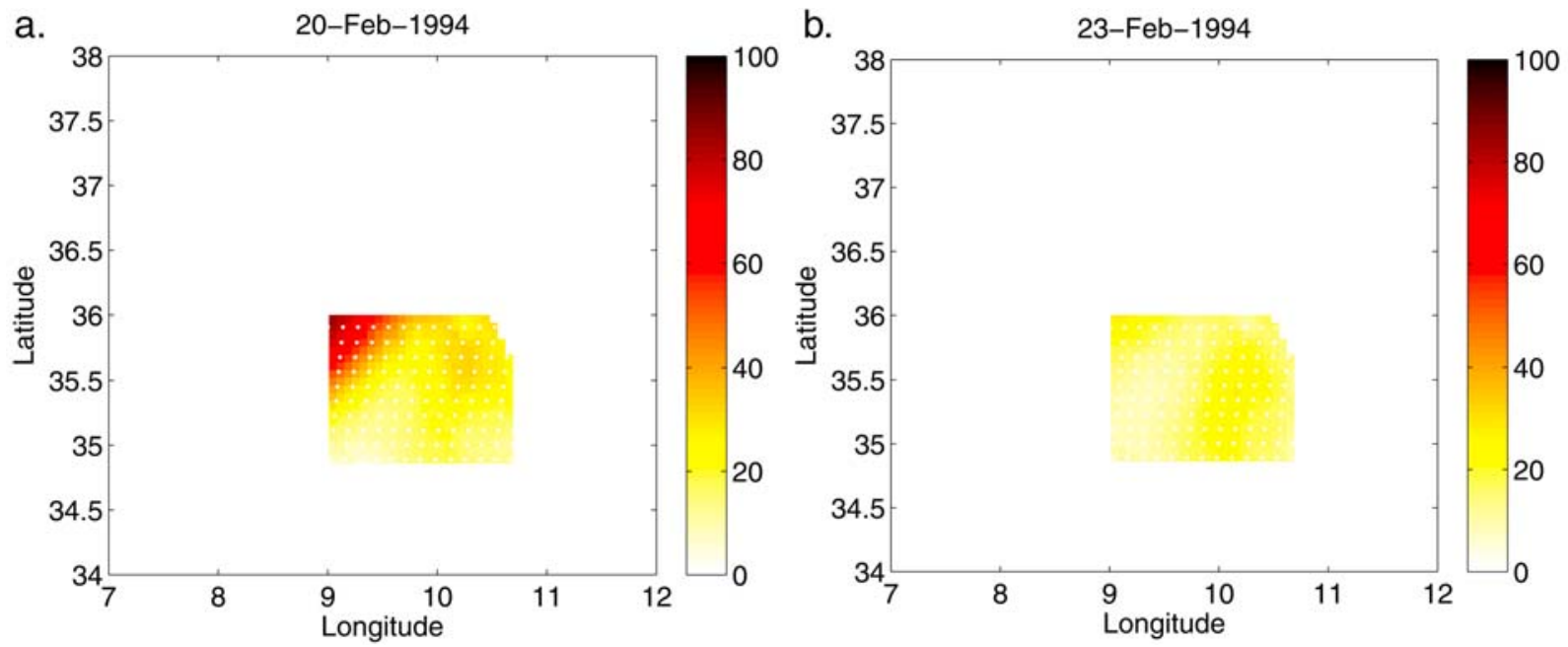

Figure 2. Illustration of $m_{s}$ ERS moisture values over the study site for 2 days: (a) The data recorded on the first date (20 February 1994), which are affected by strong spatial variability, linked to local precipitation effects. (b) The second date (23 February 1994), which after drying, has a nearly homogenously low state of moisture.

the sum of these two channels, is linked to green vegetation photosynthetic activity [Rousse et al., 1973]. A higher NDVI value indicates a greater level of photosynthetic activity [Tucker et al., 2004]. In version 3, processed by the Global Inventory Modeling and Mapping Studies (GIMMS) group, the data is corrected for intersensor differences, intrasensor degradation, orbital drift and atmospheric contamination [Pinzon et al., 2005; Tucker et al., 2004; Tucker et al., 2005]. It is also intercalibrated with the Système Probatoire d'Observation de la Terre ou Satellite Pour l'Observation de la Terre $=$ Trial Observation System for Earth Observation or Satellite for Earth Observation (SPOT4VEGETATION NDVI).

[18] Kaufmann et al. [2000], Kaufman et al. [2001], Zhou et al. [2001], and Slayback et al. [2003] highlight the reliability of this data set (e.g., no linear trend or discontinuities detected in the time series). The data provided is already synthesized on a 10 day basis, using the Maximum Value Composite (MVC) technique. This technique permits the production of nominally cloud-free images from individual, partly cloudy input scenes by selecting, from images taken over a limited period of time, the most cloud-free pixel corresponding to the same geographical location. The 10 day MVC technique is expected to ensure clear sky 10 day NDVI values. We used data recorded over the ten year period, from 1991 to 2000. The source for this data set was the Global Land Cover Facility, www.landcover.org. For the purposes of the present study, we calculated a mean NDVI data for the entire study site, using the $8 * 8 \mathrm{~km}$ spatial resolution data and monthly mean values computed from 10 day averages.

\subsection{Global Soil Wetness Project, Phase 2 Data}

[19] The soil moisture products were provided by the Global Soil Wetness Project, Phase 2 Data (GSWP-2) [Dirmeyer et al., 2006]. GSWP-2 (http://www.iges.org/gswp/) is an international initiative, which was launched by the Global Energy and Water Cycle Experiment (GEWEX) to provide global data sets of soil wetness, energy, and water fluxes, by driving 13 land surface models with state-of-the-art $1^{\circ} \times 1^{\circ}$ atmo- spheric forcing and land surface parameters over a 10 year period (1986-1995). The baseline meteorological forcing provided by GSWP-2 is based on the reanalysis made by the National Centers for Environmental Prediction and the U.S. Department of Energy. Corrections for systematic biases in the three-hourly reanalysis fields are made by comparing the data with global observed monthly climatologies from the Global Precipitation Climatology Center and the Global Precipitation Climatology Project. The daily profiles of soil moisture used in this comparison are part of the multimodel product. Analysis of the soil wetness products of GSWP-2 has shown that Land Surface Models (LSMs) can be used to provide a high-quality reproduction of soil moisture anomalies. [Guo and Dirmeyer, 2006].

\section{Analysis of Moisture Products}

\subsection{Comparison Between ERS Moistures, GSWP-2 Outputs, and Observed Rainfall}

[20] Figure 3 provides a time series comparison between ERS soil moistures, rainfall and GSWP-2 output. For the comparison of ERS and GSWP-2 data sets, three statistical parameters were calculated: the root mean square error (RMSE), the determination coefficient $\left(\mathrm{R}^{2}\right)$, and the bias between the two data sets.

[21] The soil moisture estimations derived in the present study are compared with the GSWP-2 modeled top layer (the first ten centimeters of soil) and the soil moisture profiles (100 cm depth), during the period from 1992 to 1996.

[22] The ERS surface soil moistures (Figure 3a) are correlated with precipitation events, confirming that radar estimations are qualitatively coherent. The rainfall data is provided by daily measurements taken at the Kairouan rain gauge station. Although the study zone is nonhomogeneous, it can be seen that the soil moisture peaks (for ERS and GSWP-2) occur during the rainy season (October to March), after rainfall events. Only one peak, occurring in January 1995, remains unexplained, and is probably linked to a local precipitation event not recorded by the Kairouan gauge station. 

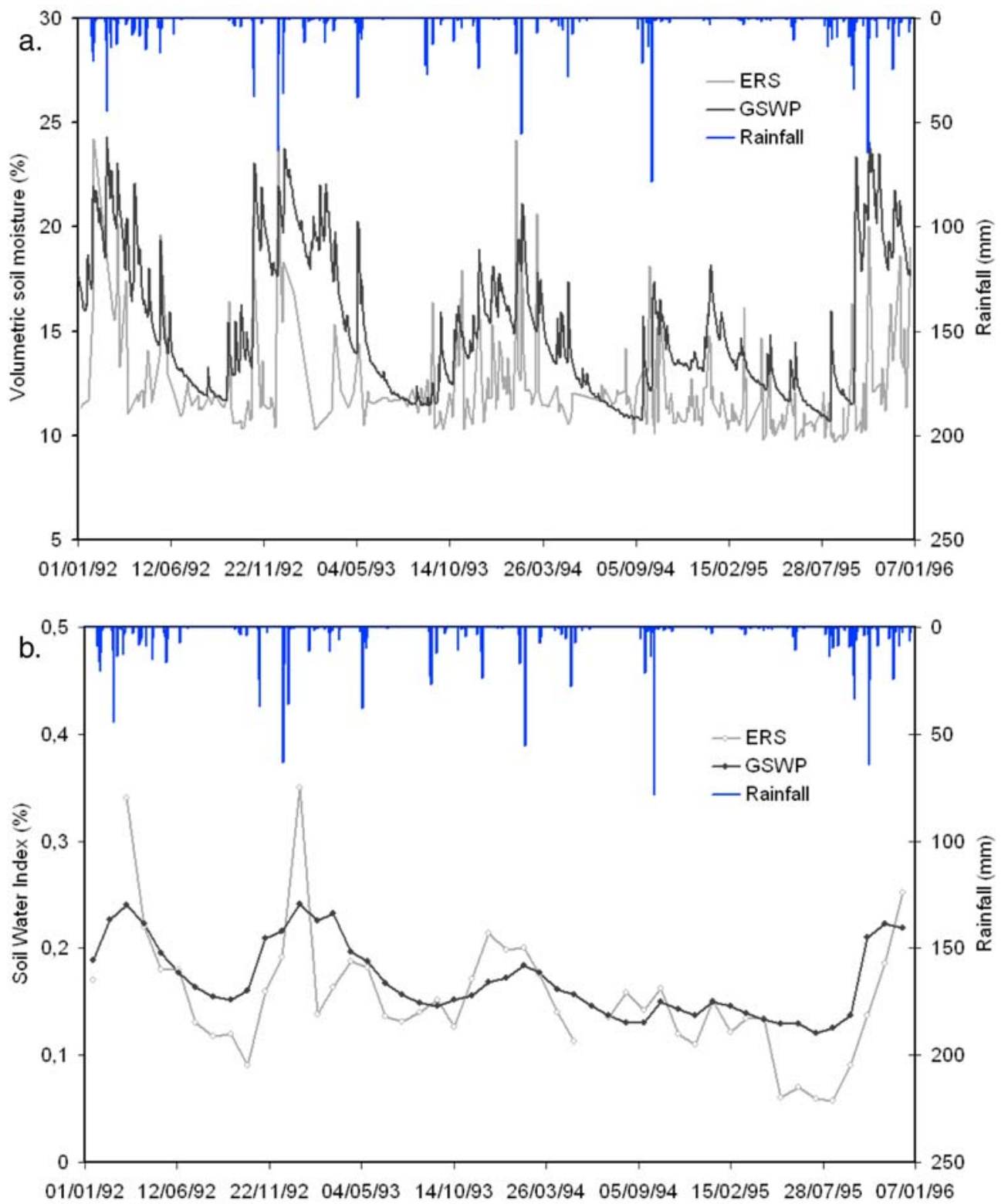

Figure 3. Intercomparison of ERS products, GSWP-2 output, and rainfall during a period of 4 years, from January 1991 to December 1995, for (a) surface moisture and (b) root-zone moistures (depth $1 \mathrm{~m}$ ).

[23] Local variations in the ERS surface products are not completely represented by the GSWP-2 outputs, because, for instance, it represents the ten first centimeters of soil, which is less influenced by atmospheric conditions (rain, wind and solar radiation) than the five first centimeters of soil (ERS radar data). The simulated soil moisture globally overestimates the ERS data (negative bias). This is consistent with previous studies, which have revealed that GSWP-2 tends to overestimate soil moisture in other African regions [Zribi et al., 2008]. The statistical parameters derived from the comparison can be considered as reasonable (RMSE $0.038 \mathrm{~m}^{3} \mathrm{~m}^{-3}$, bias $0.026 \mathrm{~m}^{3} \mathrm{~m}^{-3}$ and $\mathrm{R}^{2}$ of 0.26 ), owing to the high variability of moisture in the first few centimeters of soil [Le Morvan et al., 2008].

[24] The ERS products show high moisture values, specifically linked to rainfall events. This trend is closely related to the site's climate, characterized by high evapotranspiration values, with which the surface dries generally very quickly after a rainfall event.

[25] Figure $3 \mathrm{~b}$ provides a comparison between monthly SWI GSWP-2 outputs (1 m depth) and ERS data estimations. A good degree of coherence can be observed between the two products. A delay, of the order of several days, can be seen between rainfall events and the increase of moisture value on ERS products. The GSWP-2 simulation is able to reproduce the main ERS estimated root-zone soil moisture. The statistical parameters derived from the simulation are reasonable, with an RMSE of 0.042 , a good $\mathrm{R}^{2}(0.6)$ and a low bias of 0.015 . During the wet seasons, the ERS moisture levels could be high. We observe two maxima close to 0.35 in 1992 and 1993, which are less significant in the GSWP outputs. This difference could be explained by an underestimation of the satellite-based evaluation of evaporation in this region. In the dry years with long periods of drought, only small variations in moisture are observed. 
Table 1. Estimation of the Values of $\mu$ and $\sigma$ Characterizing the Lognormal Distributions Used to Fit Surface Moisture and RootZone Moisture Real Distributions for All Studied Years

\begin{tabular}{|c|c|c|c|c|c|c|}
\hline \multirow[b]{2}{*}{ Year } & & \multicolumn{2}{|c|}{$\mathrm{SSM}^{\mathrm{a}}$} & \multicolumn{2}{|c|}{ SWI } & \multirow{2}{*}{$\begin{array}{l}\text { Precipitation } \\
(\mathrm{mm})\end{array}$} \\
\hline & & $\mu$ & $\sigma$ & $\mu$ & $\sigma$ & \\
\hline 1993-1994 & & 2.66 & 0.56 & - & - & 262 \\
\hline 1994-1995 & Dry & 2.02 & 0.99 & 2.33 & 0.35 & 196 \\
\hline 1995-1996 & Wet & 2.93 & 0.68 & 3.03 & 0.31 & 430 \\
\hline 1996-1997 & Dry & 1.57 & 1.25 & 2.01 & 0.57 & 140 \\
\hline 1997-1998 & Wet & 2.91 & 0.39 & 2.94 & 0.21 & 421 \\
\hline 1998-1999 & & 2.35 & 0.81 & - & - & 234 \\
\hline 1999-2000 & & 2.54 & 0.55 & - & - & 213 \\
\hline $2000-2003$ & - & - & - & - & - & - \\
\hline 2004-2005 & & 2.76 & 0.49 & - & - & 327 \\
\hline $2005-2006$ & Wet & 2.93 & 0.49 & 2.92 & 0.22 & 378 \\
\hline 2006-2007 & & 2.92 & 0.48 & 2.94 & 0.23 & 344 \\
\hline
\end{tabular}

${ }^{\text {a}}$ Soil Surface Moisture.

[26] As shown in October 2004, first isolated highprecipitation events of autumn have limited effect on moisture content. In fact, this period, at the end of dry season, is characterized by very high evaporation and runoff levels.

[27] Figure 3 shows that the surface soil moisture is more variable than the root-zone soil moisture: the root-zone soil moisture is an averaged value, taken over soil depths ranging from 0 to $100 \mathrm{~cm}$, in which extreme values are generally smoothed.

\subsection{Statistics of Moisture Estimations}

[28] We observe generally strong variations between moisture estimations in the dry and wet seasons, as shown in the previous sections. In the present section, we propose to analyze the behavior of moisture distributions at the surface and for the $1 \mathrm{~m}$ root zone. We propose to fit the experimental distributions with a lognormal analytic function [Zribi et al., 2010]:

$$
f(x)=\frac{1}{\sigma \sqrt{2 \pi x}} \exp \left(-\frac{1}{2}\left(\frac{\ln x-\mu}{\sigma}\right)^{2}\right),
$$

where $\sigma$ and $\mu$ are two adjusted parameters and $x$ is the variable corresponding to the soil moisture dependence.

[29] Table 1 summarizes these values for all studied years. For the surface moisture values, we observe an increase in the value of $\mu$ during the wet season. For example, for the 19951996 wet season, the value of $\mu$ is equal to 2.93 . On the other hand, for the dry season in 1996-1997, the value of $\mu$ is equal to 1.57. Figure 4 illustrates the distribution of moisture for different years, showing the differences from one year to the next. For dry seasons, the maximum of moisture distribution is around 5\% for volumetric moisture. For wet years this maximum is higher, around $15 \%$. Presence of moistures higher than $35 \%$ is limited even in wet seasons. This is because of limited number of precipitation events and high evapotranspiration level.

[30] The same analysis was also carried out for the rootzone moisture. The variations of this parameter are less significant than for the surface moisture, as shown is Figure 5. For this reason, variations between the dry and wet seasons are less pronounced. For example, during the 1995-1996 wet season, the value of $\mu$ is equal to 3.03. On the other hand, during the 1996-1997 dry season, the value of $\mu$ is equal to 2.01. This limited difference between dry and wet seasons is typical of arid and semiarid Mediterranean regions characterized by a limited number of precipitation events even for wet years.

\section{Vegetation Cover Analysis From SWI and NDVI Estimations}

\subsection{Analysis of Correlation Between Moisture and Vegetation Dynamics}

[31] Figure 6 illustrates the vegetation NDVI dynamics over the study sites, in which SWI data are compared with the monthly precipitation values. First, we observe a qualitative correlation between precipitation and the moisture index estimations, which is particularly noticeable after rainy months. The vegetation dynamics are known to be correlated with the moisture index value [Boyer and Kramer, 1995; Rodriguez-Iturbe, 2000], and this trend can be clearly observed during the wet seasons, in particular for the case of the 1995-1996 season. In dry years, an exceptionally large decrease in moisture index is observed, associated with a stabilization or even a decrease in the NDVI, as for example in the case of the 1996-1997 season. The vegetation cycle is very sensitive to the moisture index profile, and consequently to precipitation. Only wet seasons with continuous precipitation (like 1995-1996) are characterized by a vegetation cycle with a continuous and regularly increasing NDVI, reaching a maximum at the end of March. This maximum, with limited values between 0.25 and 0.35 , illustrate the large dispersion of vegetation in the study site. During the dry period between November 1993 and February 1994, a decrease in moisture level, with near stabilization of the NDVI values, is observed over a 4 month period. In the case of the 1996-1997 season, the drought between November and January led to a decrease in moisture level, and a small decrease in the NDVI in December, following a NDVI increase at the beginning of the rainy season.

\subsection{Vegetation Cover Modeling From SWI Estimations}

[32] As shown in section 4.1, a significant correlation can be observed between the vegetation index and the previously estimated root-zone moisture values (Soil Water Index, SWI) values. In the present section, we propose to derive a model for the relationship between NDVI growth and SWI estimations. The SWI estimations from the period between 1991 and 1998 are used for this analysis. For each year, the root-zone moisture values are taken for the period between September and May, and the following model is proposed:

[33] 1. At the beginning of October, it can be assumed that the dry season has ended, with a mean NDVI of approximately 0.19 . This estimation is based on the mean value of the NDVI during the period 1991-1998.

[34] 2. At the beginning of November we observe, in general, the beginning of the vegetation cycle, with an associated increase in NDVI. We consider that the increase in vegetation estimated at the beginning of November is linked to the soil moisture profile during the month of October. We thus propose a simple linear relationship:

$$
N D V I(n o v)=a_{n o v} * S W I(o c t)+b_{n o v}
$$

where $\operatorname{NDVI}(i)$ is the NDVI index estimated at month $i$ and $\mathrm{SWI}(i-1)$ is the SWI index computed at month $i-1$. 

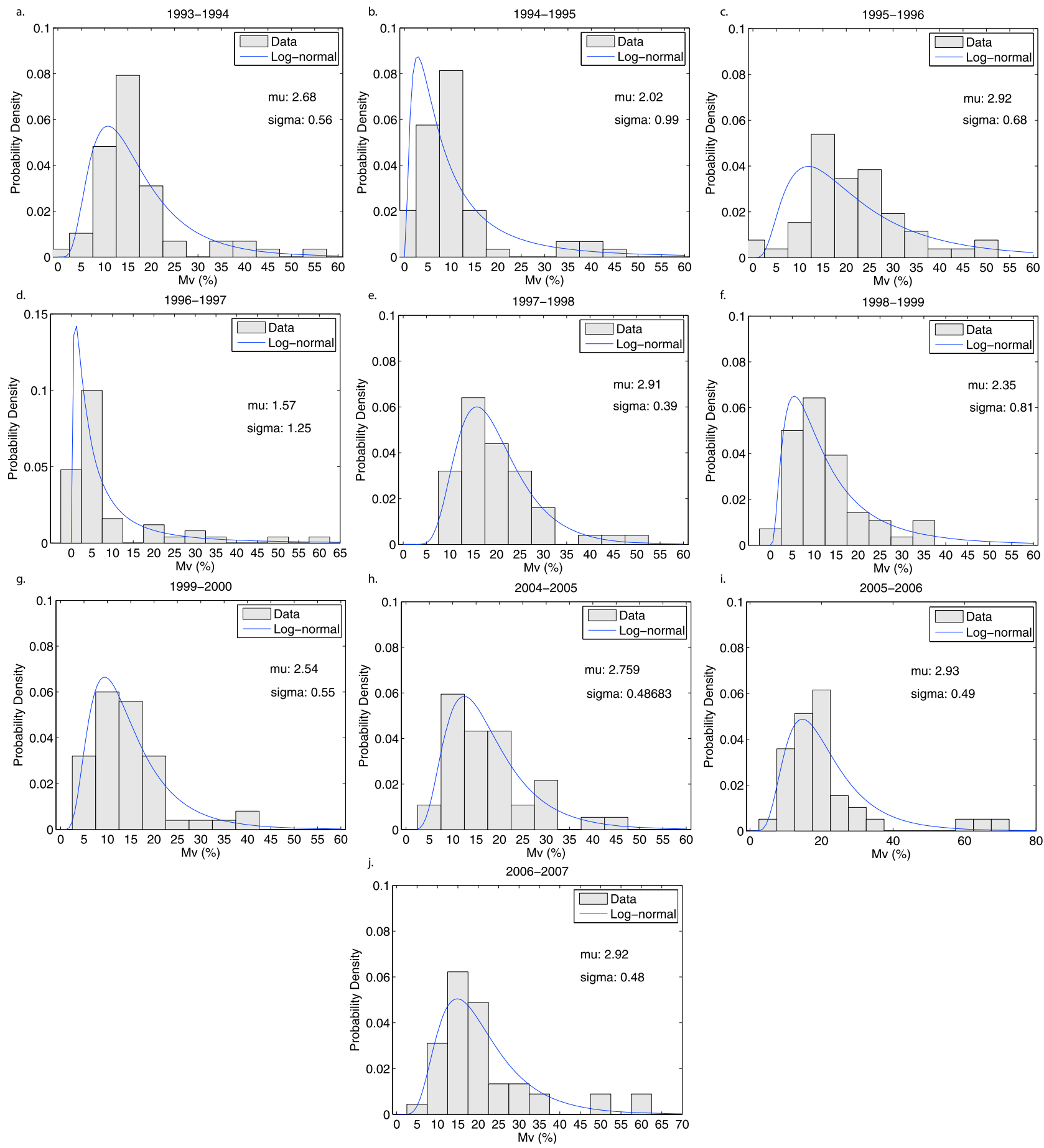

Figure 4. Surface moisture distributions for eight studied years, during the rainy season between October and May, fitted with lognormal analytical distributions.

[35] 3. At the beginning of December, we take into account the increasing values of NDVI during the month of November. This increase is linked to the soil moisture profile during the month of November:

$$
N D V I(d e c)-N D V I(n o v)=a_{d e c} * S W I_{\text {nov }}+b_{d e c} .
$$
June.
[37] We can thus consider

$$
\begin{aligned}
{\left[\begin{array}{c}
N D V I(\text { nov }) \\
N D V I(\text { dec })-N D V I(\text { nov }) \\
\ldots \\
\cdots \\
N D V I(\text { june })-N D V I(\text { may })
\end{array}\right]=} & {\left[\begin{array}{cc}
S W I(\text { oct }) & 1 \\
S W I(\text { nov }) & 1 \\
\ldots . & \\
S W I(\text { may }) & 1
\end{array}\right] } \\
& \cdot\left[\begin{array}{ll}
a_{\text {nov }} & a_{\text {dec } \ldots . . . a_{\text {june }}} \\
b_{\text {nov }} & b_{\text {dec }} \ldots . . . b_{\text {june }}
\end{array}\right] .
\end{aligned}
$$



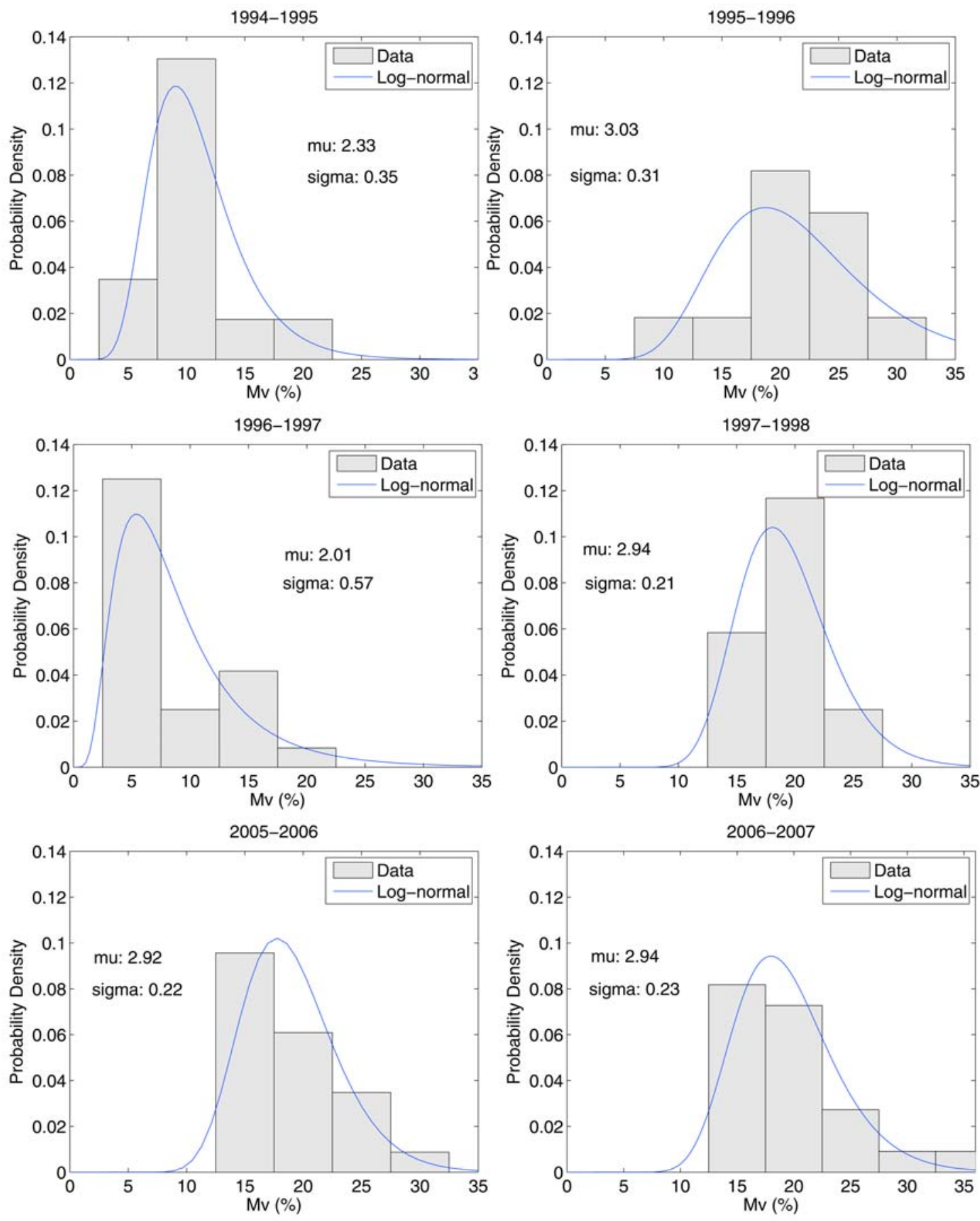

Figure 5. Distributions of SWI data for six studied years, during the rainy season between October and May, fitted with lognormal analytical distributions. 
a.

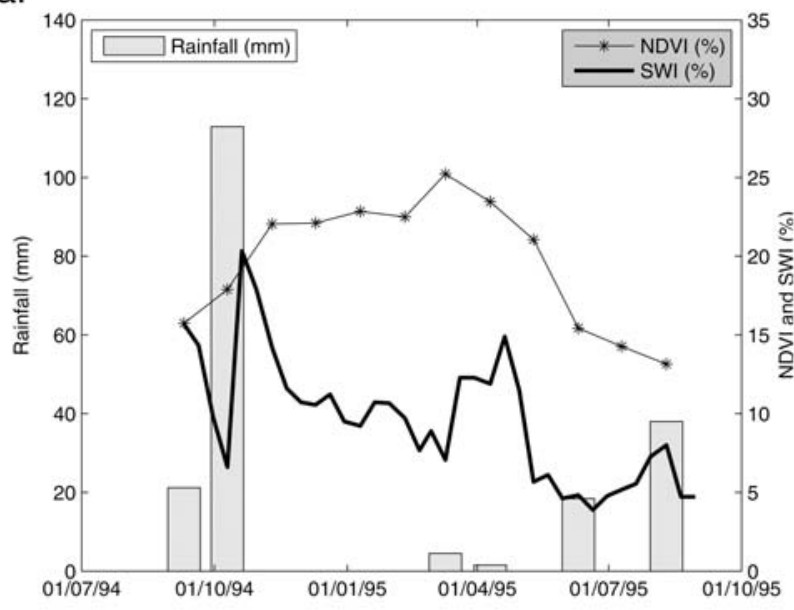

c.
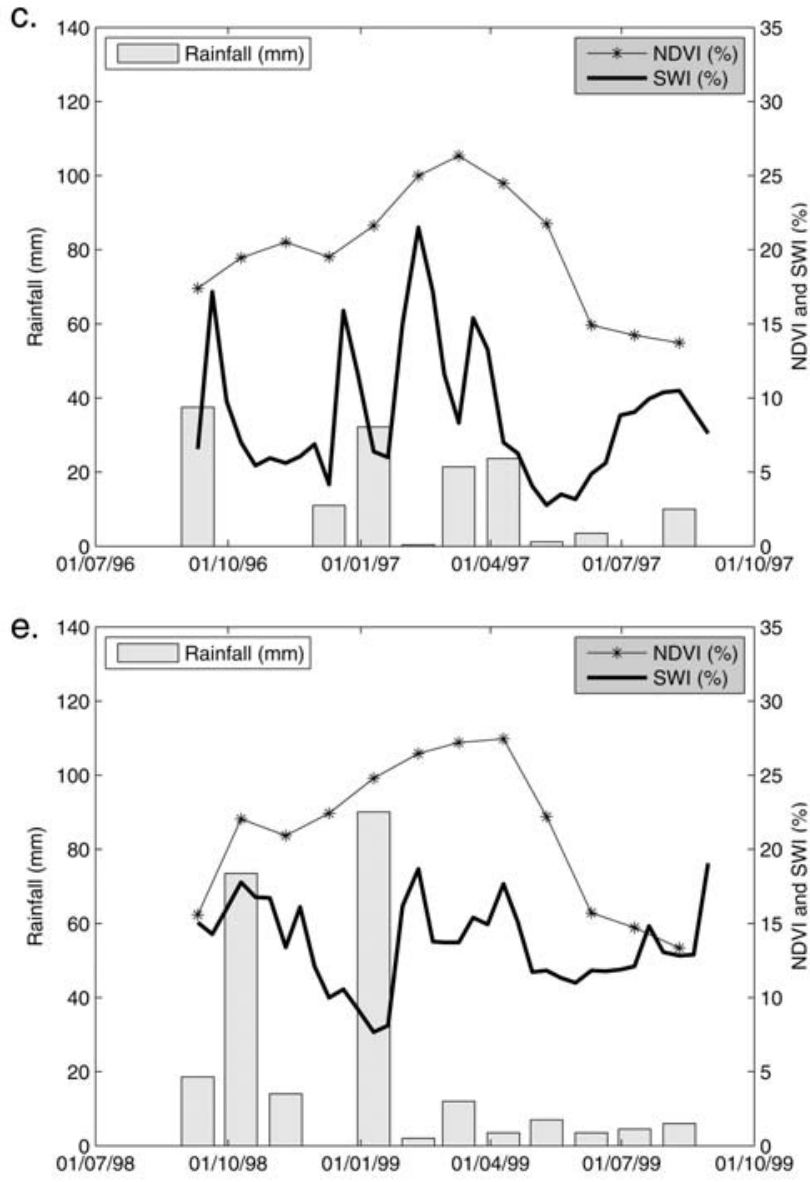

b.

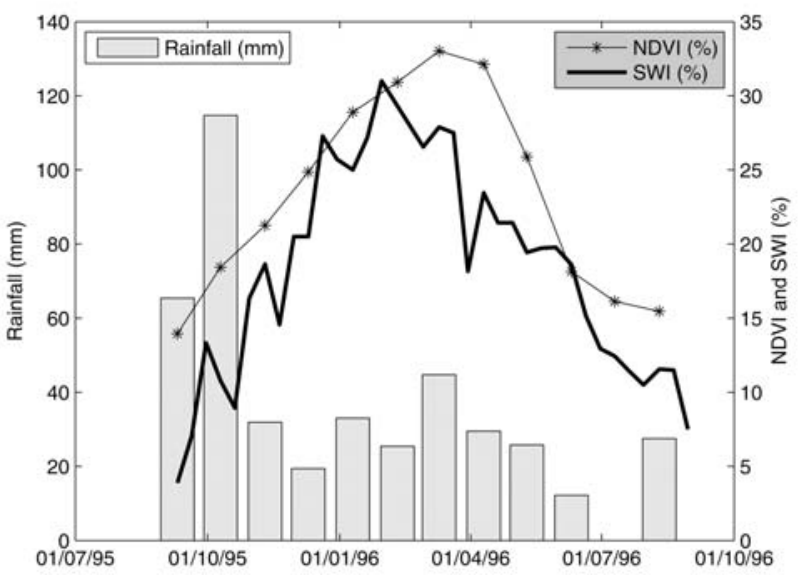

d.

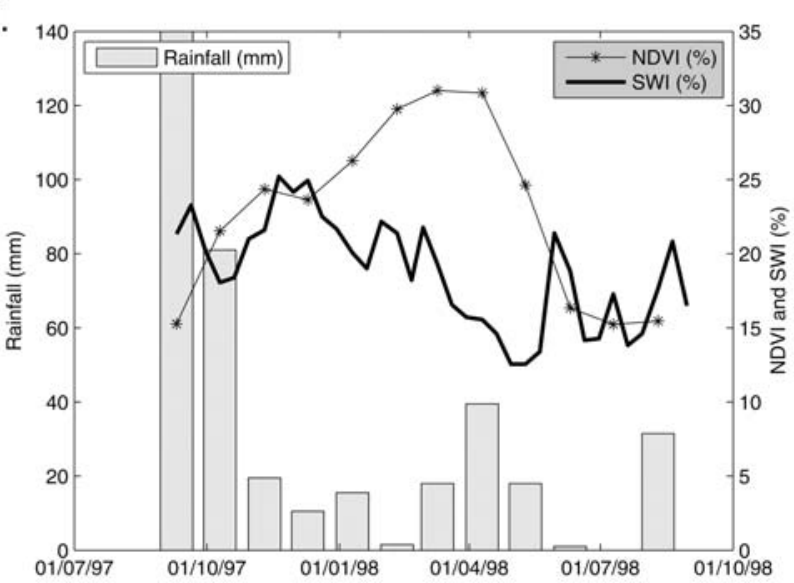

f.

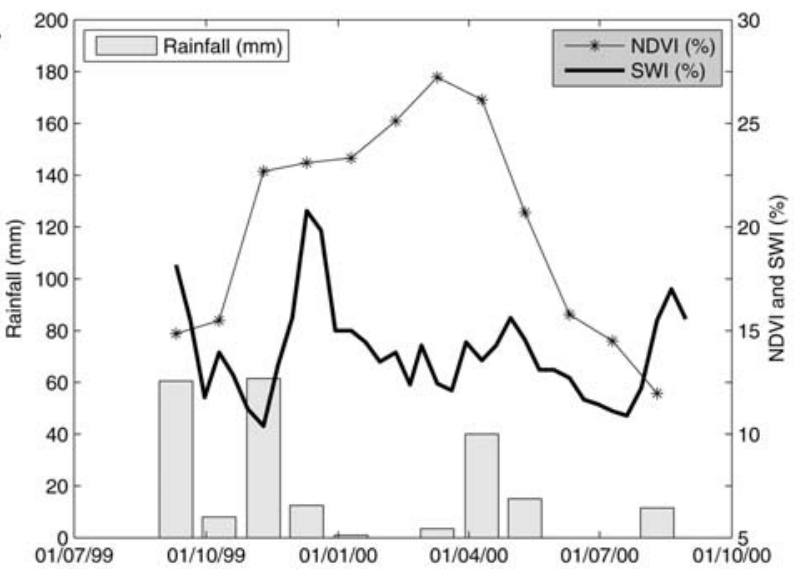

Figure 6. (a-f) Illustration of SWI and the NDVI vegetation index cycles, with precipitation, for six rainy seasons between October and May. 


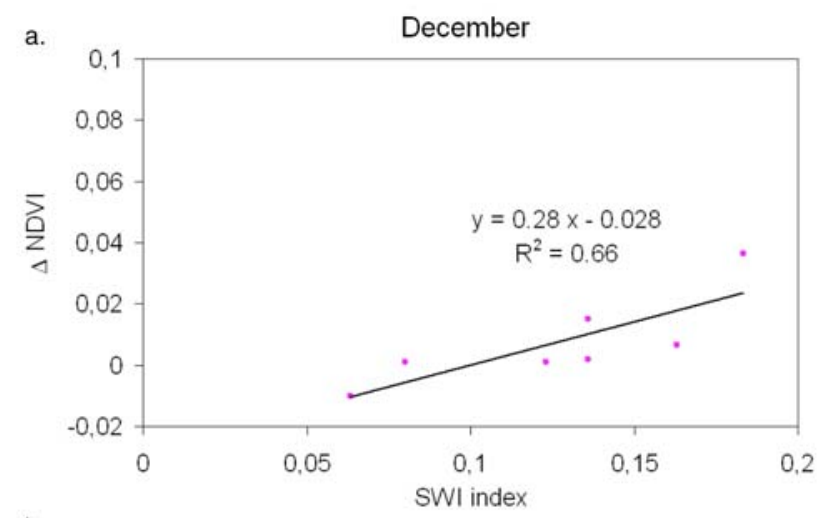

b.
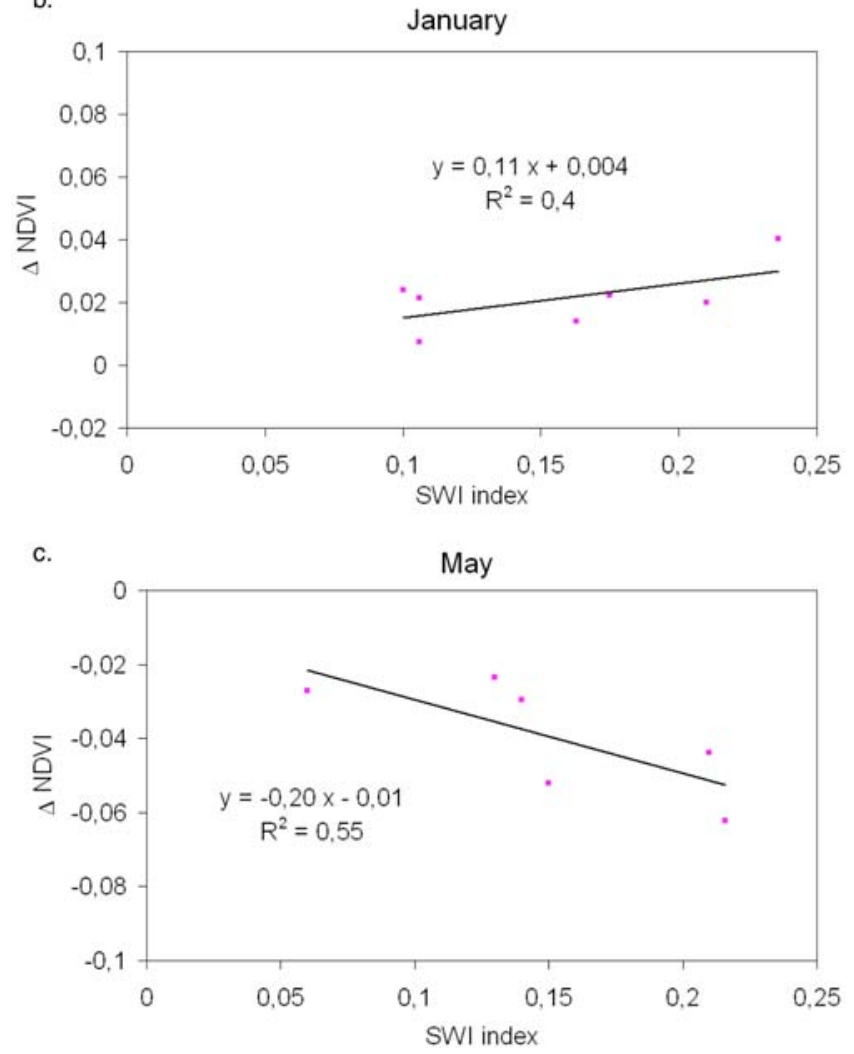

Figure 7. Illustration of the linear relationships between NDVI variation in a given month and root-zone moisture levels in the preceding month: (a) case for the month of December, (b) case for the month of January, and (c) case for the month of May.

On the basis of data from the period 1991-1998, we estimate the mean statistical parameters $a_{i}$ and $b_{i}$.

[38] Figure 7 illustrates, for 1 month in the rainy season, the derived linear relationships between the variation of NDVI values and the estimated moisture levels during the previous month. We observe, as illustrated for example in Figure $7 \mathrm{a}$, an increase in NDVI during the month of December, associated with an increase in SWI level estimated during the month of November. Using the estimated parameters $a_{i}, b_{i}$, we simulated NDVI values for all of the studied years. Figure 8 illustrates eight cases of NDVI estimations compared to real NDVI values. The six first cases correspond to six different vegetation seasons (1991-1992, 1993-1994,
1994-1995, 1995-1996, 1996-1997, 1997-1998), the data of which was used to retrieve the parameters $a_{i}$ and $b_{i}$. The seventh and eighth cases correspond to the years 1998-1999 and 1999-2000 showing a good coherence between the real and estimated NDVI values, with an RMS error lower than 0.017 . The difference between wet and dry years is illustrated for the 1995-1996 and 1996-1997 periods. For both cases, we were able to accurately simulate the NDVI data (RMSE = 0.01 and 0.014). In the first case, a maximum NDVI of approximately 0.33 is reached. For the second dry season, the maximum is also correctly retrieved, with a value of approximately 0.24 . We also correctly simulate a decrease in NDVI at the beginning of the rainy season (in November) for the 1996-1997 period.

[39] This result demonstrates the feasibility of using a simple, empirical approach to estimate the NDVI, which can be particularly useful for making rapid diagnostics in drought periods, using just two types of satellite data, without the need for physical SVAT models. Preliminary regional estimations of the expected vegetation growth could thus be proposed, without the need to analyze satellite images. With such an approach, it is also possible to make preliminary estimations of vegetation growth as a function of different scenarios.

\section{Conclusions}

[40] The objective of our paper is to propose an analysis of the relationship between soil moisture and vegetation development, using satellite databases only, for the evaluation of moisture and vegetation conditions. Validation of the ERS moisture products was proposed, using GSWP-2 outputs and rainfall data. The ERS scatterometer and GSWP-2 model data were generally able to capture the temporally variable dynamics of soil moisture over the study site. In general, the statistical performance of root-zone moisture predictions is better than that obtained for surface soil moisture. The difference between surface and root-zone moisture trends can be explained by the fact that surface soil moisture is more strongly affected by atmospheric conditions than root-zone soil moisture. An analysis of the ERS-derived moisture distributions is presented, showing the variations between wet and dry seasons.

[41] Vegetation dynamics, expressed by the NDVI derived from the AVHRR satellite database, show a high correlation with the soil moisture profile. A model is proposed, for the statistical estimation of the NDVI, over 1 month periods during the rainy season, and of the vegetation cycle, using moisture profile measurements alone taken from previous months. This simple empirical approach could be very useful for making preliminary forecasts of vegetation development, without the need for complex physical models or a large satellite database. It is important to note that the proposed approach is limited to large-scale areas, with vegetation types particularly dependent on water existing on soil profile. A local-scale analysis could introduce errors due to heterogeneity of soil texture or vegetation types.

[42] It could be used for making appropriate and timely decisions in response to drought. Vegetation coverage could then be estimated 1 month before using satellite moisture products with microwave (active and passive) and thermal infrared sensors, or more simply from ground profile measurements, which are representative of the temporal variations 
a.

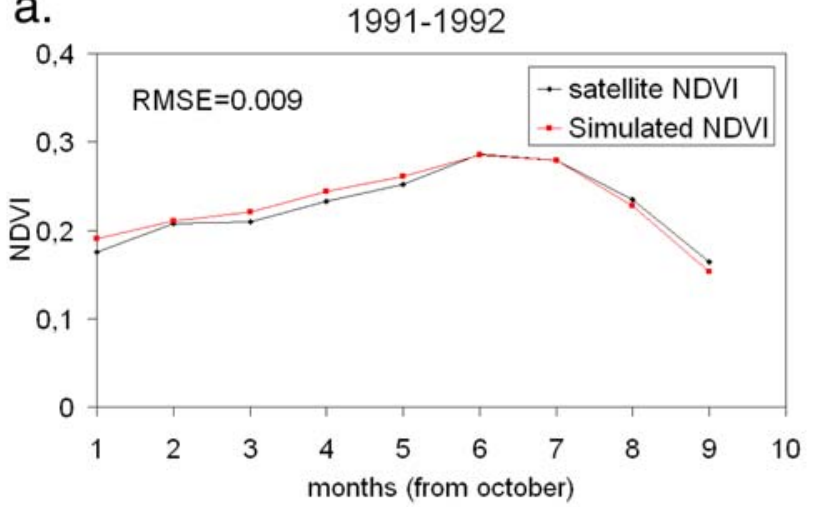

C.

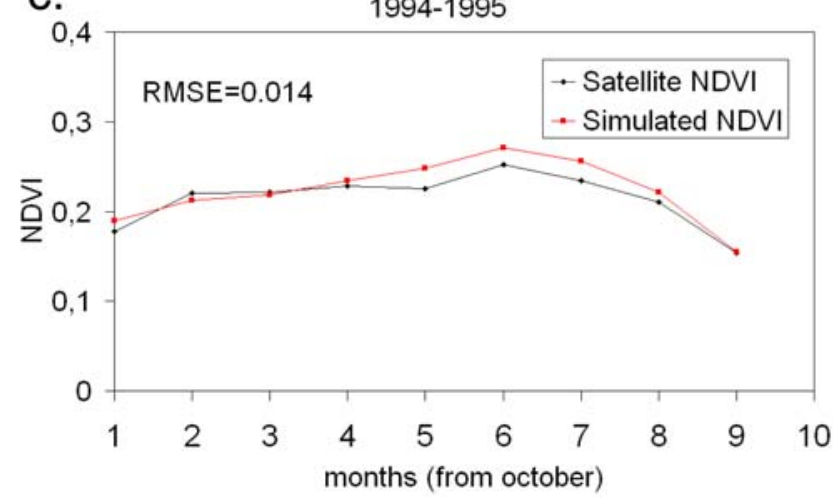

e.

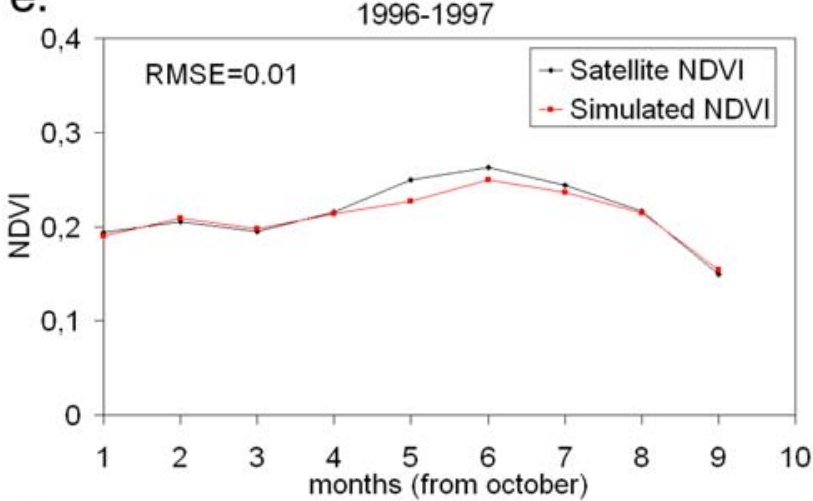

g.

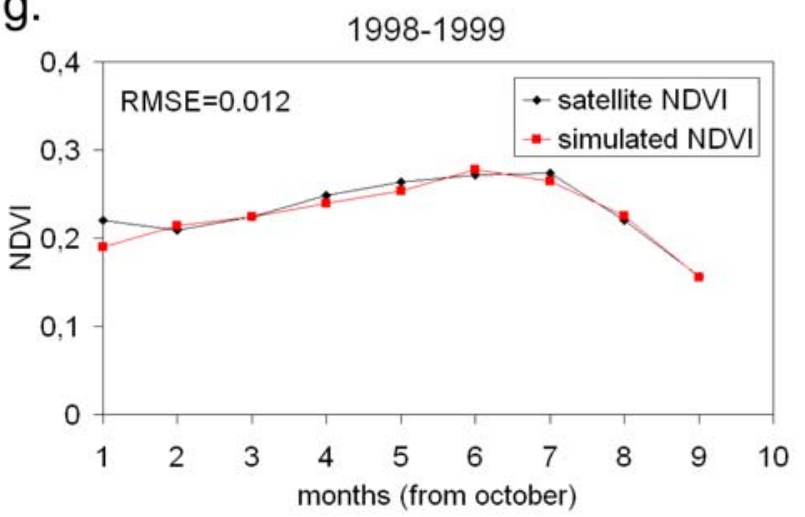

b.

1993-1994

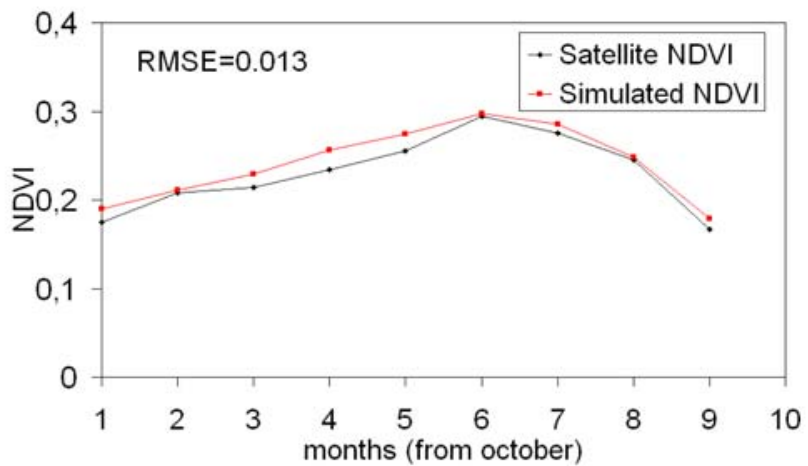

d.
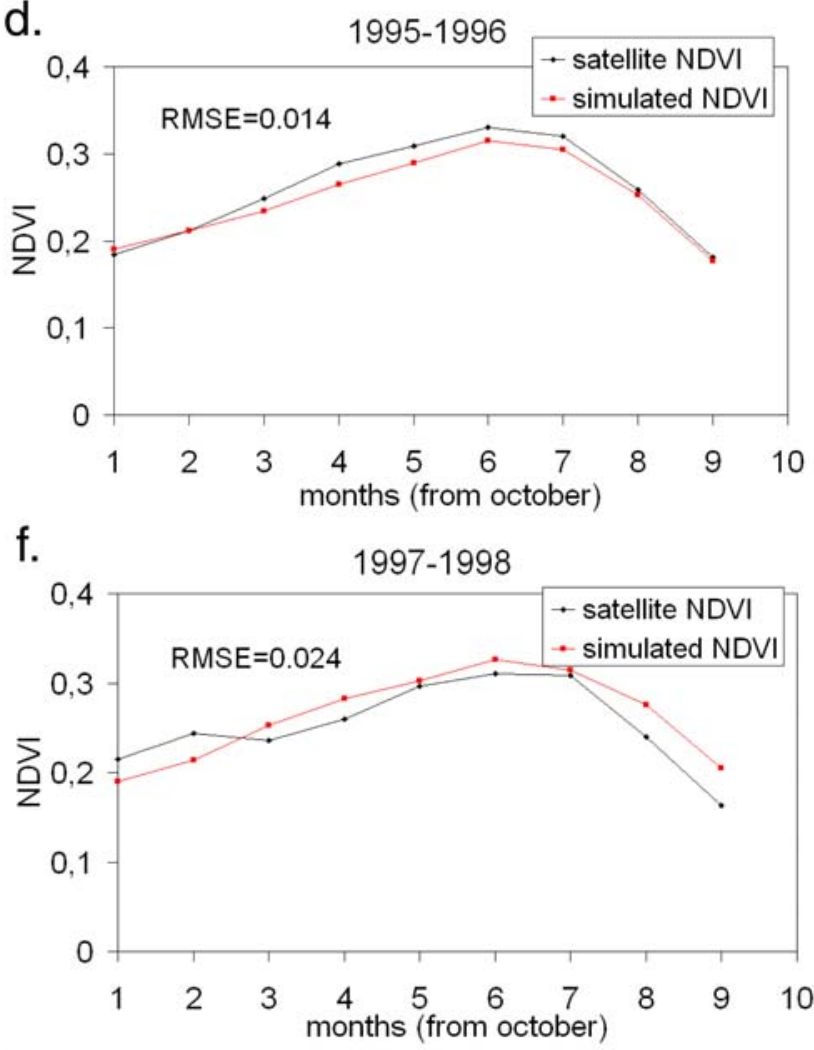

h.

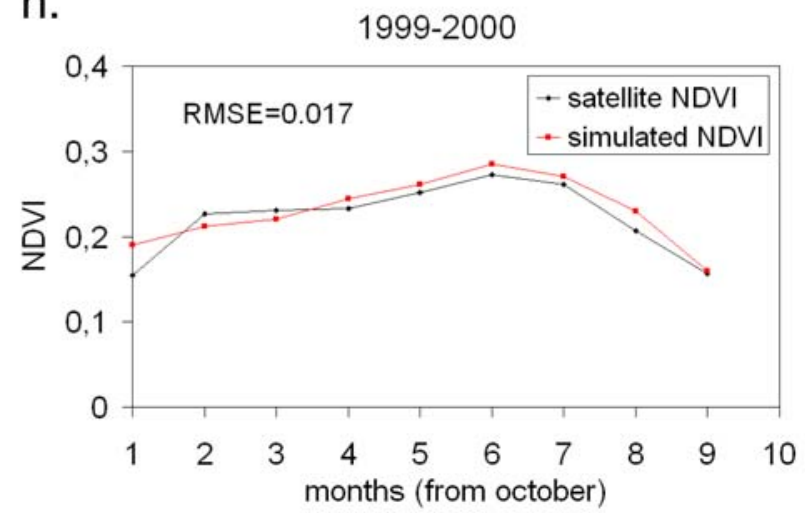

Figure 8. $(\mathrm{a}-\mathrm{h})$ Comparison between satellite NDVI estimations and the results obtained using the proposed NDVI simulations, for eight studied years. 
of moisture in a study site [Albergel et al., 2008]. This approach could be implemented operationally, to improve early warning systems, and would be complementary to other forecast methodologies based on climate analysis [e.g., Funk and Brown, 2006]. Future work will include an analysis of this approach in more local scales, for different types of vegetation, using in particular the Moderate Resolution Imaging Spectroradiometer (MODIS) and the VEGETATION instrument on SPOT $1 \mathrm{~km}$ scale data.

[43] Acknowledgments. We would like to thank Vienna University for the use of their global moisture products, CRDA-Kairouan (Tunisia) for precipitation measurements, Paul Dirmeyer and his team at the Center for Ocean Land Atmosphere studies (COLA) for their contributions toward the development of the Global Soil Wetness Project, and Stéphanie Guidon (G-Eau laboratory) for all details concerning the study site. This study was funded by two programs: the French National Remote Sensing Program (PNTS) and Agence Universitaire de la Francophonie (AUF).

\section{References}

Albergel, C., C. Rudiger, D. Carrer, J. C. Calvet, N. Fritz, V. Naeimi, Z. Bartalis, and S. Hasenauer (2008), An evaluation of ASCAT surface soil moisture products with in-situ observations in south western France, Hydrol. Earth Syst. Sci. Discuss., 5, 2221-2250.

Anyamba, A., and C. J. Tucker (2005), Analysis of Sahelian vegetation dynamics using NOAA-AVHRR NDVI data from 1981-2003, J. Arid Environ., 63(3), 596-614, doi:10.1016/j.jaridenv.2005.03.007.

Barbosa, H. A., A. R. Huete, and W. E. Baethgen (2006), A 20-year study of NDVI variability over the Northeast Region of Brazil, J. Arid Environ., 67(2), 288-307, doi:10.1016/j.jaridenv.2006.02.022.

Beven, K. J., and J. Fisher (1996), Remote sensing and scaling in hydrology, in Scaling up in Hydrology Using Remote Sensing, edited by J. B. Stewart et al., pp. 1-18, John Wiley, New York.

Boyer, J., and P. Kramer (Eds.) (1995), Water Relations of Plants and Soils, Academic, Sand Diego, Calif.

Brubaker, K. L., and D. Entekhabi (1996), Analysis of feedback mechanisms in land-atmosphere interaction, Water Resour. Res., 32(5), 1343-1357, doi:10.1029/96WR00005.

Ceballos, A., K. Scipal, W. Wagner, and J. Martínez-Fernández (2005), Validation of ERS scatterometer-derived soil moisture data in the central part of the Duero Basin, Spain, Hydrol. Processes, 19, 1549-1566, doi:10.1002/hyp.5585.

Dai, A., K. E. Trenberth, and T. Qian (2004), A global data set of Palmer Drought Severity Index for 1870-2002: Relationship with soil moisture and effects of surface warming, J. Hydrometeorol., 5, 1117-1130, doi:10.1175/JHM-386.1.

Dirmeyer, P. A., X. Gao, M. Zhao, Z. Guo, T. Oki, and N. Hanasaki (2006), The Second Global Soil Wetness Project (GSWP-2): Multimodel analysis and implications for our perception of the land surface, Bull. Am. Meteorol. Soc., 87(10), 1381-1397, doi:10.1175/BAMS-87$10-1381$.

Douville, H., F. Chauvin, and H. Broqua (2001), Influence of soil moisture on the Asian and African monsoons. Part I: Mean monsoon and daily precipitation, J. Clim., 14(11), 2381-2403, doi:10.1175/1520-0442 (2001)014<2381:IOSMOT>2.0.CO;2.

Eltahir, E. A. B., and C. Gong (1996), Dynamics of wet and dry years in West Africa, J. Clim., 9(5), 1030-1042, doi:10.1175/1520-0442(1996) 009<1030:DOWADY>2.0.CO;2.

Entekhabi, D., I. Rodriguez-Iturbe, and F. Castelli (1996), Mutual interaction of soil moisture state and atmospheric processes, J. Hydrol., 184(1-2), 3-17, doi:10.1016/0022-1694(95)02965-6.

Farrar, T. J., S. E. Nicholson, and A. R. Lare (1994), The influence of soil type on the relationships between NDVI, rainfall, and soil moisture in semiarid Botswana. II. NDVI response to soil moisture, Remote Sens. Environ., 50(2), 121-133, doi:10.1016/0034-4257(94)90039-6.

Funk, C. C., and M. E. Brown (2006), Intra-seasonal NDVI change projections in semi-arid Africa, Remote Sens. Environ., 101(2), 249-256, doi:10.1016/j.rse.2005.12.014.

Goward, S. N., C. J. Tucker, and D. G. Dye (1985), North American vegetation patterns observed with the NOAA-7 advanced very high resolution radiometer, Plant Ecol., 64(1), 3-14, doi:10.1007/BF00033449.
Guo, Z., and P. A. Dirmeyer (2006), Evaluation of the Second Global Soil Wetness Project soil moisture simulations: 1. Intermodel comparison, J. Geophys. Res., 111, D22S02, doi:10.1029/2006JD007233.

Heim, R. R. (2002), A review of twentieth-century drought indices used in the United States, Bull. Am. Meteorol. Soc., 83(8), 1149-1165.

Jackson, T. J., J. Schmugge, and E. T. Engman (1996), Remote sensing application to hydrology: Soil moisture, Hydrol. Sci. J., 41, 517-530, doi:10.1080/02626669609491523.

Kaufman, Y. J., D. Tanre, O. Dubovik, A. Karnieli, and L. A. Remer (2001), Absorption of sunlight by dust as inferred from satellite and ground-based remote sensing, Geophys. Res. Lett., 28, 1479-1482.

Kaufmann, R. K., L. Zhou, Y. Knyazikhin, N. Shabanov, R. Myneni, and C. J. Tucker (2000), Effect of orbital drift and sensor changes on the time series of AVHRR vegetation index data, IEEE Trans. Geosci. Remote Sens., 38, 2584-2597.

Koster, R. D., et al. (2004), Regions of strong coupling between soil moisture and precipitation, Science, 305, 1138-1140, doi:10.1126/science. 1100217.

Lacombe, G., B. Cappelaere, and C. Leduc (2008), Hydrological impact of water and soil conservation works in the Merguellil catchment of central Tunisia, J. Hydrol., 359(3-4), 210-224, doi:10.1016/j.jhydrol.2008.07.001.

Leduc, C., et al. (2007), Impacts of hydrological changes in the Mediterranean zone: Environmental modifications and rural development in the Merguellil catchment, central Tunisia, Hydrol. Sci. J., 52(6), 1162-1178, doi:10.1623/hysj.52.6.1162.

Le Morvan, A., M. Zribi, N. Baghdadi, and A. Chanzy (2008), Soil moisture profile effect on radar signal measurement, Sensors, 8, 256-270, doi: $10.3390 / \mathrm{s} 8010256$.

Moulin, S., L. Kergoat, N. Viovy, and G. Dedieu (1997), Global-scale assessment of vegetation phenology using NOAA/AVHRR satellite measurements, J. Clim., 10(6), 1154-1170, doi:10.1175/1520-0442(1997) $010<1154:$ GSAOVP $>2.0 . \mathrm{CO} ; 2$.

Nicholson, S. E., and T. J. Farrar (1994), The influence of soil type on the relationships between NDVI, rainfall, and soil moisture in semiarid Botswana. I. NDVI response to rainfall, Remote Sens. Environ., 50(2), 107-120, doi:10.1016/0034-4257(94)90038-8.

Ntale, H. K., and T. Y. Gan (2003), Drought indices and their application to East Africa, Int. J. Climatol., 23, 1335-1357, doi:10.1002/joc.931.

Paloscia, S., P. Pampaloni, S. Pettinato, and E. Santi (2008), A comparison of algorithms for retrieving soil moisture from ENVISAT/ASAR images, IEEE Trans. Geosci. Remote Sens., 46, 3274-3284, doi:10.1109/ TGRS.2008.920370.

Paris Anguela, T., M. Zribi, F. Habets, S. Hasenauer, and C. Loumagne (2008), Analysis of surface and root soil moisture dynamics with ERS scatterometer and the hydrometeorological model SAFRAN-ISBAMODCOU at Grand Morin watershed (France), Hydrol. Earth Syst. Sci., 5, 1903-1926.

Pellarin, T., J.-C. Calvet, and W. Wagner (2006), Evaluation of ERS scatterometer soil moisture products over a half-degree region in southwestern France, Geophys. Res. Lett., 33, L17401, doi:10.1029/2006GL027231.

Peters, A. J., M. D. Eve, E. H. Holt, and W. G. Whitford (1997), Analysis of desert plant community growth patterns with high temporal resolution satellite spectra, J. Appl. Ecol., 34, 418-432, doi:10.2307/2404887.

Pinzon, J., M. E. Brown, and C. J. Tucker (2005), Satellite time series correction of orbital drift artefacts using empirical mode decomposition, in Hilbert-Huang Transform: Introduction and Applications, edited by N. Huang, pp. 167-186, World Sci., Singapore.

Richard, Y., and I. Poccard (1998), A statistical study of NDVI sensitivity to seasonal and interannual rainfall variations in Southern Africa, Int. J. Remote Sens., 19(15), 2907-2920.

Rodriguez-Iturbe, I. (2000), Ecohydrology: A hydrologic perspective of climate-soil-vegetation dynamics, Water Resour. Res., 36(1), 3-9, doi:10.1029/1999WR900210.

Rousse, J. W., R. H. Haas, J. A. Schell, and D. W. Deering (1973), Monitoring the vernal advancement and retrogradation (green wave effect) of natural vegetation, Prog. Rep. RSC 1978-1, Remote Sens. Cent., Tex. A\&M Univ., College Station, Tex.

Saux-Picart, S., C. Ottlé, B. Decharme, C. André, M. Zribi, A. Perrier, B. Coudert, N. Boulain, B. Cappelaere, and L. Descroix (2010), Water and energy budgets simulation over the AMMA-Niger super-site spatially constrained with remote sensing data, J. Hydrol., 375, 287-295.

Slayback, D. A., J. E. Pinzon, S. O. Los, and C. J. Tucker (2003), Northern Hemisphere photosynthetic trends 1982-1999, Global Change Biol., 9, 1-15, doi:10.1046/j.1365-2486.2003.00507.x. 
Tucker, C. (1979), Red and photographic infrared linear combinations for monitoring vegetation, Remote Sens. Environ., 8(2), 127-150, doi:10.1016/0034-4257(79)90013-0.

Tucker, C. J., J. E. Pinzon, and M. E. Brown (2004), Global inventory modeling and mapping studies, 15 April 1994, NA94apr15b.n11-VIg, Version 2.0, Global Land Cover Facil., Univ. of Md., College Park, Md. (Available at http://www.landcover.org/data/gimms)

Tucker, C. J., J. E. Pinzon, M. E. Brown, D. Slayback, E. W. Pak, R. Mahoney, E. Vermote, and N. El Saleous (2005), An extended AVHRR 8-km NDVI dataset compatible with MODIS and SPOT vegetation NDVI data, Int. J. Remote Sens., 26(20), 4485-4498, doi:10.1080/ 01431160500168686 .

Ulaby, F. T., P. C. Dubois, and J. van Zyl (1996), Radar mapping of surface soil moisture, J. Hydrol., 184(1-2), 57-84, doi:10.1016/0022-1694(95) 02968-0.

Wagner, W. (1998), Soil moisture retrieval from ERS scatterometer data, Ph.D. dissertation, Vienna Univ. of Technol., Vienna.

Wagner, W., and K. Scipal (2000), Large-scale soil moisture mapping in western Africa using the ERS scatterometer, IEEE Trans. Geosci. Remote Sens., 38, 1777-1782, doi:10.1109/36.851761.

Wagner, W., J. Noll, M. Borgeaud, and H. Rott (1999a), Monitoring soil moisture over the Canadian Prairies with the ERS scatter meter, IEEE Trans. Geosci. Remote Sens., 37, 206-216, doi:10.1109/36.739155.

Wagner, W., G. Lemoine, and H. Rott (1999b), A method for estimating soil moisture from ERS scatterometer and soil data, Remote Sens. Environ., 70, 191-207, doi:10.1016/S0034-4257(99)00036-X

Wagner, W., G. Lemoine, M. Borgeaud, and H. Rott (1999c), A study of vegetation cover effects on ERS scatterometer data, IEEE Trans. Geosci. Remote Sens., 37, 938-948, doi:10.1109/36.752212.

Walker, J. P., and P. R. Houser (2001), A methodology for initializing soil moisture in a global climate model: Assimilation of near-surface soil mois- ture observations, J. Geophys. Res., 106, 11,761-11,774, doi:10.1029/ 2001JD900149.

Zhou, L., C. J. Tucker, R. K. Kaufmann, D. Slayback, V. S. Shabanov, and R. B. Myneni (2001), Variations in northern vegetation activity inferred from satellite data of vegetation index during 1981 to 1999, J. Geophys. Res., 106, 20,069-20,084, doi:10.1029/2000JD000115.

Zribi, M., S. Le Hégarat-Mascle, C. Ottlé, B. Kammoun, and C. Guerin (2003), Surface soil moisture estimation from the synergetic use of the (multi-incidence and multi-resolution) active microwave ERS wind scatterometer and SAR data, Remote Sens. Environ., 86(1), 30-41, doi:10.1016/S0034-4257(03)00065-8.

Zribi, M., C. André, and B. Decharme (2008), A method for soil moisture estimation in Western Africa based on the ERS scatterometer, IEEE Trans. Geosci. Remote Sens., 46, 438-448, doi:10.1109/TGRS.2007.904582.

Zribi, M., M. Pardé, P. De Rosnay, F. Baup, L. Descroix, and C. Ottlé (2010), ERS scatterometer surface soil moisture analysis over two sites in south and north of Sahel region in Western Africa, J. Hydrol., 375, $253-261$.

A. Chehbouni, B. Duchemin, and M. Zribi, CESBIO (CNRS, CNES, IRD, UPS), 18 Ave. Edouard Belin, bpi 2801, F-31401 Toulouse, CEDEX 9, France. (mehrez.zribi@ird.fr)

S. Hasenauer and W. Wagner, Institute of Photogrammetry and Remote Sensing, Vienna University of Technology, Gusshausstrasse 27-29, A-1040 Vienna, Austria.

Z. Lili, INAT, 43 Ave. Charles Nicolle, 1082 Tunis-Mahrajène, Tunisia. T. Paris Anguela, LATMOS, 10-12 Ave. de l'Europe, F-78140 Vélizy, France. 